\title{
Beginning mathematical writing assignments
}

\author{
Alexander Halperin, Colton Magnant, Zhoujun Magnant *
}

August 6, 2019

\begin{abstract}
Writing assignments in any mathematics course always present several challenges, particularly in lower-level classes where the students are not expecting to write more than a few words at a time. Developed based on strategies from several sources, the two small writing assignments included in this paper represent a gentle introduction to the writing of mathematics and can be utilized in a variety of low-to-middle level courses in a mathematics major.
\end{abstract}

\section{Introduction}

Many math majors mistakenly believe that they will not be expected to write as part of their coursework. Many algebra, precalculus, and calculus classes require little to no mathematical writing, even though opportunities abound in problem-solving, exposition, or even self-reflection after an assignment. Students, in turn, become accustomed to this lack of writing and fail to see the logical nature of mathematics and ultimately struggle with expressing themselves through writing.

The short writing assignments presented in this article represent our attempt to solve several problems at once. First, these assignments provide a guided step into the formal writing of mathematics. Second, they were used as part of a larger research project comparing the progress of students from two different classes at two different universities: one class with an intervention of a larger writing assignment (see Magnant, Nasseh, \& Flateby, 2016) and the other without. We omit the details of this larger assignment as our focus here is on the smaller writing assignments. Finally, these assignments, with minimal background introduction, can be assigned in virtually any course within a math

*Salisbury University, Clayton State University, Georgia Southern University, adhalperin@salisbury.edu, dr.colton.magnant@gmail.com, zmagnant@georgiasouthern.edu. Copyright 2019 Alexander Halperin, Colton Magnant, and Zhoujun Magnant. This work is licensed under a Creative Commons AttributionNonCommercial 4.0 International License (http://creativecommons.org/licenses/by-nc/4.0/).

${ }^{\dagger}$ Submitted, 7/18/2017; Accepted, 4/27/2019. 
program. In short, they were developed as both a measurement tool and an introduction to formal mathematical writing.

Students wrote one proof for each assignment. In the first writing assignment, students determined whether a cat-and-mouse chase could pass exactly once through every open door and window in a house, whose floor plan was given. The second assignment, "Poker Hands," required students to determine the winner of a three-player poker game by ranking three poker hands from least to most probable. For each of these assignments, students submitted their proof along with an abstract, an introduction, their results, and a conclusion.

The writing assignments were developed using a combination of strategies and ideas from Walvoord (2014), Bahls (2012), Bean (2011), and Crannell et al. (2004) as well as ideas stemming from personal experience taking and teaching courses in mathematics. The assignments foster effective writing habits and, at the same time, develop students' skills in the areas of argumentation, analysis, and synthesis. In order to prove their claimed solution, students must argue using credible evidence and supporting logic. Effective analysis and description of the situation in both assignments provides the framework necessary for a successful complete solution. Finally, an element of synthesis is expected in the summarizing conclusion where students must consider a possible "natural" next step as a direction for future work.

Both writing assignments were assigned in each of two different classes, one at each of the two different universities. Salisbury University (SU) is a mid-sized public regional comprehensive university, while Georgia Southern University (GSU) is a large public regional comprehensive university. At $\mathrm{SU}$, the assignments were used in an introductory discrete mathematics course. At GSU, the assignments were used in a course on introduction to proofs called Mathematical Structures. Each class had about 30 students, primarily second-year undergraduates with a handful of first-year and third-year students as well. In a survey of the students in the class, most said they had never written more than a sentence or two in a math class. Both classes were learning Claim-Proof form ${ }^{1}$ of mathematical writing so an additional goal of these assignments was to reinforce this writing style.

In the rest of this essay, we describe how we used these assignments to teach students effective writing in mathematics. We begin with a discussion of the in-class group activities before describing our findings when we allowed the students to work independently. Finally, we offer some suggestions for what these findings mean for the teaching of mathematics and mathematical writing.

\section{Whole Class Practice}

For each of the writing assignments, students spent a day in class solving a related problem followed by a day devoted to formulating their ideas into paragraphs. In doing so, they mimicked the standard mathematical problem-solving process: first 
discover the solution and then formally write it up. The mathematical content of the assignments was deliberately involved - students needed to spend the entire period discussing, understanding and answering the problem - but not terribly difficult so that students could focus on the writing after class. The class was designed to be an interactive experience: students worked on the problem in groups of three to four. The instructor toured the classroom to sort out misconceptions and to ensure that all group members were engaged. With around fifteen minutes left in the period, the instructors halted group work to have students lead a discussion about the solution along with their problem-solving process.

The next day, we moved away from problem-solving and began our focus on writing by first handing out the assignment, which required a formal essay presentation of their solution(s). Neither assignment was long, requiring only two to three pages. The primary focus of both assignments was on the process of the writing and how to explain solutions clearly, precisely, and concisely. We required that each paper contain the four semi-standard sections found in most mathematical papers: an abstract, introduction, main results, and conclusion. The assignment document contained brief summaries of what type of content was expected in each section, and we provided ongoing classroom discussion, guidance, and clarification throughout the process, including our reasoning for requiring the four-section format. Armed with at least the bulk of a solution to the mathematical content of the questions and, in most cases, a rough outline of their solutions, the students proceeded home to complete the papers. Anecdotally, students suggested that they were better able to synthesize information through the writing than standard exercises, and they appreciated the experience. Students were expected to complete each assignment in about a week.

In both classes at the two different universities, the student products were scored using the same writing rubric (see the first appendix for a sample from the rubric, 3 of the 17 traits) for consistency. This rubric was developed primarily based on the well-thought-out Georgia Southern University Quality Enhancement Plan writing rubric (2015) but also drew on insights from Bahls (2012). This rubric was used since it provides a reliable and consistent measure of the different components of the written products that we wanted to measure for this project.

\section{Trying It on Their Own}

For each assignment, after practicing together as a class, we moved toward independent work and assigned them the formal writing problem. Recall that the first assignment involves a cat chasing a mouse around a house, and the question involves deciding (and proving) whether or not the pair can pass through all of the openings (doors and windows) in the house without repeating any. In the second question, a heated debate over a poker match requires a determination of which hand is least likely to appear and, therefore, more valuable.

The playful nature ${ }^{2}$ of both questions was intended to welcome, rather than intimidate, 
students when they first read the assignment in class. Immediately after reading the problem, students received a handout with questions pertaining to the paper. For the rest of the class period, students worked in groups to discover a solution. The instructor toured the classroom, answering minor questions about the mathematics when necessary, and then led a discussion at the end regarding the solution. We detail this approach for each assignment in the following sections. In subsequent class meetings, the instructors reminded the students of due dates, and correspondingly where they should be in the process of the writing. Relevant discussions of revision and editing were also included in classroom discussions.

Students collaborated during class but were expected to each write their own separate paper, as opposed to Latulippe and Latulippe's assignments (2014), in which three to four student groups turned in a single essay. This was to ensure that each student was responsible for their own writing, as we prioritized writing over problem-solving. Although the QEP rubric weights math and writing equally, most students understood the solutions to both writing assignments by the end of the lecture, meaning that their scores for the mathematical part should have been high with little variance.

\section{Cat and Mouse}

For the "Cat and Mouse" assignment, students first explored the famous "Seven Bridges of Königsberg problem" (Paoletti, 2011), in which a traveler tries, in a continuous route, to cross each of seven bridges in Königsberg, Prussia exactly once (see supplementary materials for this in-class assignment). After some trial and error, students discovered that such a route is impossible, along with the realization that the lack of solution must be proved, rather than asserted. Listed below the problem statement were the steps to the proof, out of order ${ }^{3}$, for students to rearrange. At the end of the exercise, the class recapped the argument to the instructor in their own words. The instructor then asked students to partition the solution into paragraphs to best organize the ideas presented in the proof. From there, students had the necessary mathematical tools to attempt the first writing assignment. As a matter of fact, the "Cat and Mouse" problem has the same solution as the Seven Bridges problem: the fact that there exist more than two rooms with an odd number of doorways plus windows means the cat and mouse cannot pass through every open door and window exactly once.

Given that the students could now easily solve the "Cat and Mouse" problem, the main challenge of this assignment was for students to present a mathematical solution with its proper motivation and background. The following day, we demonstrated examples of complete written solutions to similar problems and discussed advantages and disadvantages of each along with recommendations for improvement. By writing mostly about the framing of a problem, students were meant to see that a mathematical paper requires far more than a problem statement and solution. Additionally, in following the example solutions discussed in class, they were forced to write in paragraph form, a first for most of them in a math class. 
According to the rubric scores, students particularly struggled with audience awareness by failing to provide the necessary context and definitions needed for full understanding. Although the target audience was not explicitly stated in the assignment prompt, the students were instructed to write as if to an audience of their peers. This audience was purposely chosen to encourage peer review in the revision process. Broadly speaking, other areas of the rubric were in the acceptable range, especially the proof write-up. This was not surprising since the question is simple to understand, and the students already have a correct proof from their class notes.

\section{Poker Hands}

The purpose of the poker writing assignment was to again show students that mathematics is primarily carried out in words, rather than symbols. Further, we wanted students to understand the power of the "combinatorial proof," in which quantities are counted using basic multiplication, factorials, and combinations. A problem that could take hundreds of algebraic calculations by brute force can sometimes be answered in a few short sentences in a combinatorial proof, hence making it the far more desirable option.

The writing assignment on poker hands came at the end of a week's worth of combinatorics lessons. Students had studied the combination " $n$ choose $r$," or $\left(\begin{array}{l}n \\ r\end{array}\right)$, and learned its combinatorial definition (" $\left(\begin{array}{c}n \\ r\end{array}\right)$ is the number of ways to choose a subset with $r$ elements out of a set with $n$ elements") as well as derived its algebraic formula

$\left(\begin{array}{l}n \\ r\end{array}\right)=\frac{n !}{(n-r) ! r !}$.

Further, they had dealt with counting problems, including a poker hand example and several more involving playing cards. Most importantly, students had learned to solve these problems by viewing $\left(\begin{array}{l}n \\ r\end{array}\right)$ through its combinatorial definition, which emphasizes exposition and conceptual understanding over calculation. Thus, they understood that the algebraic formula is more a technical result and is only used at the end of a problem to find an exact numerical answer.

At the beginning of the first class, we asked students to work in groups to count the number of each type of poker hand (see the writing assignment, including the crossedout hands). The professor roamed the classroom, sorting out any misconceptions and correcting what are usually small errors. By the end of class, all student groups had counted all or nearly all poker hands.

The main task for the writing assignment was for students to formally write their classroom discoveries as a logical sequence of steps, in which they reformulate a poker hand into the values and/or suits that were chosen to form it. Of course, they still needed to provide background for this problem, but that was usually simpler than the previous writing assignment. Most found the poker hand situation more gripping than the cat-mouse chase, and many were eager to research the history of poker (and, in some cases, discuss it at great length). In fact, some students took such interest with the history of poker that it dominated the Introduction. To remedy this and keep the focus 
on the problem at hand, future assignments will specify a limit to the "history" portion of the Introduction, and the rubric will be adjusted accordingly.

This being the second assignment, the instructors were able to discuss the issues with audience awareness in the previous assignment by providing and discussing specific examples in class so the scores in this area were slightly improved over the "Cat and Mouse" assignment. Other areas where the students showed a bit of weakness was paragraph structure, transition between paragraphs, and overall flow. In particular, several students listed calculations for the three chosen hands with almost no discussion in between. One way to combat this misunderstanding may be to create a different rubric and provide it to students with the assignment. We discuss this at the end of the next section and give such a rubric in the supplementary materials.

\section{General Conclusion and Future Plans}

Our modest goal was to use these writing assignments as an introduction to mathematical writing, opening the door to the world of written mathematics. That said, given the ease in which students were able to state their solutions, we believe we should add a degree of difficulty to each assignment. For the "Cat and Mouse" assignment, this could mean asking for a more general proof that any multigraph with more than two vertices of odd degree has no Eulerian trail. For the poker assignment, we are considering requiring students to find the probability of a "high card," (the most difficult to explain), including a wild card (i.e., a card that can take on any value or suit), or perhaps a variant game with a different number of card values and/or suits. ${ }^{4}$

In the future, we hope to further incorporate a small reflection piece after each assignment in which the students will reflect on their process of writing, which may (should) include revision, peer-review, editing, etc. We hope to use this information to enlighten students to the effective writing processes that not only make them stronger writers but also, more immediately, result in better scores. Although explicit mention of process writing was not included in the assignment prompts, it was discussed in class, particularly when discussing outlines, revision, and peer review. The students outlined their solutions in class and were encouraged to review and revise each other's writing outside of class since these were intended to be shorter writing assignments. We intend to include more deliberate details about process writing in future iterations.

Broadly speaking, students show better performance when the audience for the assignment is clear, supporting the theory in the MAA Instructional Practices Guide (2018). We were pleasantly surprised at the amount and effectiveness of the peer reviews and intend to be more intentional about the audience in further iterations of these assignments, in particular, including explicit statements about audience in the assignment prompts.

We also plan to develop more advanced and challenging problems to further the students' writing experience later in their mathematical careers. In both of these assignments, although students spent a day on each of the "Seven Bridges of Königsberg" and poker 
hands, the actual mathematical solutions were short, no longer than a paragraph each. Although our students appreciated the succinctness of a well-written mathematical proof, we do want them to experience writing a proof that, by itself, spans at least a page or, better still, requires steps or lemmas to prove.

One further change, particularly for the poker assignment, could be to require students to research a real-world combinatorial question. While similar to the approach used by Pinter (Pinter, 2014), we would require students to find a question outside of class instead of citing previous course material. Since, unlike Pinter, our classes contain exclusively math majors and minors, we believe the added component of researching combinatorial problems outside of class would be a fair, albeit challenging, additional requirement. Such an assignment would require group work for both discovering and solving the problem. To ensure that students choose an appropriately difficult problem, we would have students first hand in their problems before writing the essay.

We have also considered changing the rubric to something shorter, more readable, and with specific guidelines (e.g., "Utilize $\left(\begin{array}{l}52 \\ 5\end{array}\right)$ in each proof"). We believe this may reduce student forgetfulness or misunderstanding of assignment requirements, such as including ClaimProof form for all five poker hand results or making conjectures in the conclusion. We have included an outline of such a rubric for the poker hands assignment in supplementary materials.

\section{Assignment:}

See the Supplementary Files for this article at thepromptjournal.com for a PDF facsimile of the original formatting of this assignment.

\section{Writing Rubric Excerpt}

\begin{tabular}{|c|c|c|c|c|c|}
\hline & $\begin{array}{l}\text { Does not } \\
\text { meet }(1)\end{array}$ & Attempted (2) & $\begin{array}{l}\text { Approaches } \\
(3)\end{array}$ & Meets (4) & $\begin{array}{l}\text { Exceeds } \\
(5)\end{array}$ \\
\hline $\begin{array}{l}\text { Assign- } \\
\text { ment } \\
\text { Require- } \\
\text { ments }\end{array}$ & $\begin{array}{l}\text { The } \\
\text { writer is } \\
\text { off topic } \\
\text { and/or } \\
\text { omits } \\
\text { most or } \\
\text { all of the } \\
\text { assign- } \\
\text { ment } \\
\text { require- } \\
\text { ments. }\end{array}$ & $\begin{array}{l}\text { The writer } \\
\text { addresses the } \\
\text { appropriate } \\
\text { topic but only } \\
\text { superficially } \\
\text { addresses the } \\
\text { assignment } \\
\text { requirements. }\end{array}$ & $\begin{array}{l}\text { The writer } \\
\text { addresses } \\
\text { the } \\
\text { appropriate } \\
\text { topic and } \\
\text { meets the } \\
\text { assignment } \\
\text { require- } \\
\text { ments. }\end{array}$ & $\begin{array}{l}\text { The writer } \\
\text { addresses the } \\
\text { appropriate } \\
\text { topic and } \\
\text { clearly and } \\
\text { correctly } \\
\text { fulfills each } \\
\text { aspect of the } \\
\text { assignment } \\
\text { require- } \\
\text { ments. }\end{array}$ & $\begin{array}{l}\text { The writer } \\
\text { addresses } \\
\text { the appro- } \\
\text { priate topic } \\
\text { and clearly, } \\
\text { correctly, } \\
\text { and } \\
\text { concisely } \\
\text { fulfills each } \\
\text { aspect of } \\
\text { the } \\
\text { assignment } \\
\text { requirements }\end{array}$ \\
\hline
\end{tabular}




\begin{tabular}{|c|c|c|c|c|c|}
\hline & $\begin{array}{l}\text { Does not } \\
\text { meet (1) }\end{array}$ & Attempted (2) & $\begin{array}{l}\text { Approaches } \\
\text { (3) }\end{array}$ & Meets (4) & $\begin{array}{l}\text { Exceeds } \\
(5)\end{array}$ \\
\hline $\begin{array}{l}\text { Reasoning } \\
\text { (Proof) }\end{array}$ & $\begin{array}{l}\text { The } \\
\text { logical } \\
\text { connec- } \\
\text { tion of } \\
\text { the argu- } \\
\text { ment is } \\
\text { weak, } \\
\text { leaving } \\
\text { the argu- } \\
\text { ment or } \\
\text { explana- } \\
\text { tion } \\
\text { unclear. } \\
\text { A "proof } \\
\text { by exam- } \\
\text { ple" falls } \\
\text { here. }\end{array}$ & $\begin{array}{l}\text { The reasoning } \\
\text { offers apparent } \\
\text { support for the } \\
\text { argument, but } \\
\text { the argument } \\
\text { or explanation } \\
\text { is weak. }\end{array}$ & $\begin{array}{l}\text { Collectively, } \\
\text { the logic } \\
\text { offers } \\
\text { adequate } \\
\text { support for } \\
\text { the } \\
\text { argument, } \\
\text { but the } \\
\text { argument or } \\
\text { explanation } \\
\text { remains } \\
\text { unclear or } \\
\text { incomplete. }\end{array}$ & $\begin{array}{l}\text { Collectively, } \\
\text { the logic } \\
\text { supports and } \\
\text { advances the } \\
\text { argument or } \\
\text { explanation } \\
\text { of the proof. }\end{array}$ & $\begin{array}{l}\text { Collectively, } \\
\text { the logical } \\
\text { steps offer } \\
\text { compelling } \\
\text { support } \\
\text { which } \\
\text { clearly } \\
\text { advances } \\
\text { the } \\
\text { argument } \\
\text { or explana- } \\
\text { tion of the } \\
\text { proof. }\end{array}$ \\
\hline $\begin{array}{l}\text { Quality of } \\
\text { Details }\end{array}$ & $\begin{array}{l}\text { Details } \\
\text { are su- } \\
\text { perficial } \\
\text { or do } \\
\text { not } \\
\text { develop } \\
\text { the } \\
\text { proof. }\end{array}$ & $\begin{array}{l}\text { Details are } \\
\text { loosely related } \\
\text { to the proof. } \\
\text { Many do not } \\
\text { provide } \\
\text { supporting } \\
\text { statements, } \\
\text { credible } \\
\text { evidence, or the } \\
\text { examples } \\
\text { necessary to } \\
\text { explain or } \\
\text { persuade } \\
\text { adequately. }\end{array}$ & $\begin{array}{l}\text { Details are } \\
\text { related to } \\
\text { the proof } \\
\text { but } \\
\text { inconsist- } \\
\text { ently } \\
\text { provide } \\
\text { supporting } \\
\text { statements, } \\
\text { credible } \\
\text { evidence, or } \\
\text { the } \\
\text { examples } \\
\text { necessary to } \\
\text { explain or } \\
\text { persuade } \\
\text { adequately. }\end{array}$ & $\begin{array}{l}\text { Details } \\
\text { provide } \\
\text { supporting } \\
\text { statements, } \\
\text { credible } \\
\text { evidence, or } \\
\text { the examples } \\
\text { necessary to } \\
\text { explain or } \\
\text { persuade } \\
\text { adequately. }\end{array}$ & $\begin{array}{l}\text { Compelling } \\
\text { details } \\
\text { provide } \\
\text { supporting } \\
\text { statements, } \\
\text { credible } \\
\text { evidence, } \\
\text { or the } \\
\text { examples } \\
\text { necessary } \\
\text { to explain } \\
\text { or persuade } \\
\text { effectively. }\end{array}$ \\
\hline
\end{tabular}

\section{Assignment 1: Cat and Mouse}

A cat chases a mouse in and out of a house. Due to the hot weather and malfunctioning air conditioner, all doors and windows are open. This provides a rousing game of tag, as both the mouse and the cat are small enough to fit through all doorways and window frames. Is it possible for the cat and mouse to run through every doorway and window 
frame exactly once? If so, then draw such a route. If not, then prove that such a route is not possible.

Search online for "house plan diagram" and select a sufficiently detailed plan of a house for this exercise. Is it possible for the cat and mouse to run through every doorway and window frame exactly once? If so, then draw such a route. If not, then prove that such a route is not possible.

Make sure to write up your proof in Claim-Proof form, stating the answer at the beginning with a claim and using complete sentences and paragraphs in your proof. Be sure to include any figures that may assist the reader when reading your answer. You may assume that the reader is familiar with basic graph theory terminology.

Your paper should consist of the following sections:

- Abstract: briefly state the intent of your paper,

- Introduction: state the problem and explain its background,

- Main Result(s): state and prove your result,

- Conclusion: state similar or generalized conjectures that arise from your result.

\section{Assignment 2: Poker Hands}

During a 5-card Poker game between five of the most famous (fictional) Poker players, tension rises when James Bond, Kenny Rogers, and Rusty Ryan each go "all in," putting a combined $\$ 5$ million into the pot. The players reveal their hands to find that

- James Bond has a

- Kenny Rogers has a and

- Rusty Ryan has a

No one wants to let go of any money; each player demands to know the exact likelihood of each hand; only then can the winner be declared. Since all hands are different, this will require five separate calculations.

As the dealer, you must determine the winner. Find the general probabilities of each of the five Poker hands - that is, you must state how likely it would be to get each of the hands after drawing 5 cards from a 52-card deck (consisting of 13 values, each with 4 suits). Naturally, the hand with the lowest probability wins. It is important that you prove your answers accurately and concisely, in no more than 2 or 3 pages.

Make sure to write up your proofs in Claim-Proof form, stating the answer at the beginning with a claim and using complete sentences and paragraphs in your proof. Write a separate claim and proof for each player's hand. While you may not need any figures to assist you, you must use proper notation when referring to combinations and permutations. 
Your paper should consist of the following sections:

- Abstract: briefly state the problem and the intent of your paper,

- Introduction: state the basic history and rules of Poker; also define combinations and probability,

- Main Result(s): state and prove your result(s),

- Conclusion: summarize your work, and make conjectures that arise from your result(s).

You may choose any 5 of the following non-crossed out Poker hands:

- Royal Flush: The values 10, J, Q, K, A of the same suit.

- Straight Flush: Any 5 consecutive values with the same suit.

- Four of a Kind: All 4 copies of the same value and one additional card.

- Full House: Any 3 copies of one value and any 2 copies of a different value.

- Flush: Any 5 cards of the same suit that do not form a Royal Flush or Straight Flush.

- Three of a Kind: Any 3 copies of one value and any 2 different values.

- Two Pair: Any 2 copies of one value and any 2 copies of another value and one additional value.

- Pair: Any 2 copies of one value and any 3 different values.

- High Card: All other Poker hands not previously described. 


\section{The Königsberg Bridge Problem}

Problem 1: Consider the following layout in Königsburg, Prussia:

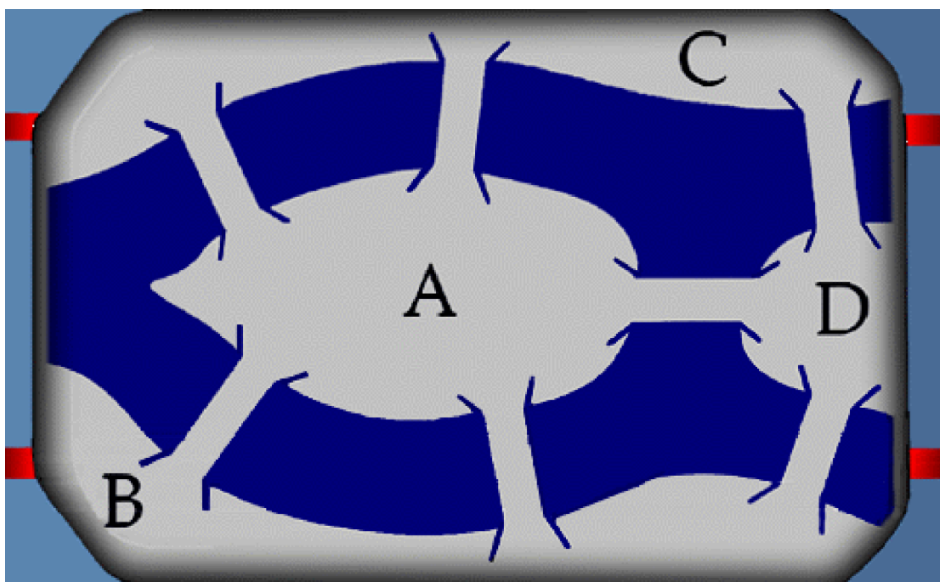

Figure 1: Map for Problem 1

Is there a route through the city that crosses each bridge exactly once?

There are two ways we can try to figure out the answer:

1. If we think such a route exists, then we should find an example.

2. If we think such a route does not exist, then we must prove it.

Which method is easier? \#1 Does that mean that method is correct? No

Using the map on the next page, try the easier method for a few minutes, and see what you get.

Try several different routes until you get a solution, or until you think a solution doesn't exist.

Answer to Problem 1: No. (Euler, 1736)

To see this, we can view the map of Königsburg as a graph. Each land mass is represented by a vertex, and each bridge is represented by an edge. A route through the graph that uses an edge at most one time is called a trail.

The steps of the claim and proof are posted below, but in the wrong order. Unscramble the steps to obtain a complete and correct claim and proof of the problem.

\section{Proof:}

2. Call this graph $G$. Hence, we see that $G$ consists of vertices and edges.

\section{Claim:}


4. There is no route through Königsburg that traverses every bridge exactly once.

5. As a result, there cannot exist a trail in $G$ that contains every edge of $G$.

6. Note that each vertex in $G$ touches an number of edges.

7. It now suffices to prove the claim, "There is no trail in $G$ that contains every edge of G."

8. However, each vertex in $G$ touches an number of edges.

9. Hence, if $T$ contains every edge in $G$, then $T$ must have at least two vertices that touch an even number of edges in $T$.

10.

11. Except for possibly the beginning and ending vertices, every vertex in a trail $T$ touches an (circle one) even/odd number of edges in $T$.

12. We represent the map of Königsburg with a graph in the following way: draw a vertex for each land mass and an edge for each bridge.

13. This is because each middle vertex in $T$ is entered by one edge and then exited by another.

Using the above reasoning, we can generalize the answer to Problem 1 as follows:

Proposition 2: If a graph $G$ has precisely zero or two vertices of odd degree, then there exists a trail containing every edge of ${ }^{*} \mathrm{G}$.

Using Proposition 2, which of the following graphs might contain a trail with every edge? For those that cannot, can you succinctly explain why? For those that might, can you find such a trail?

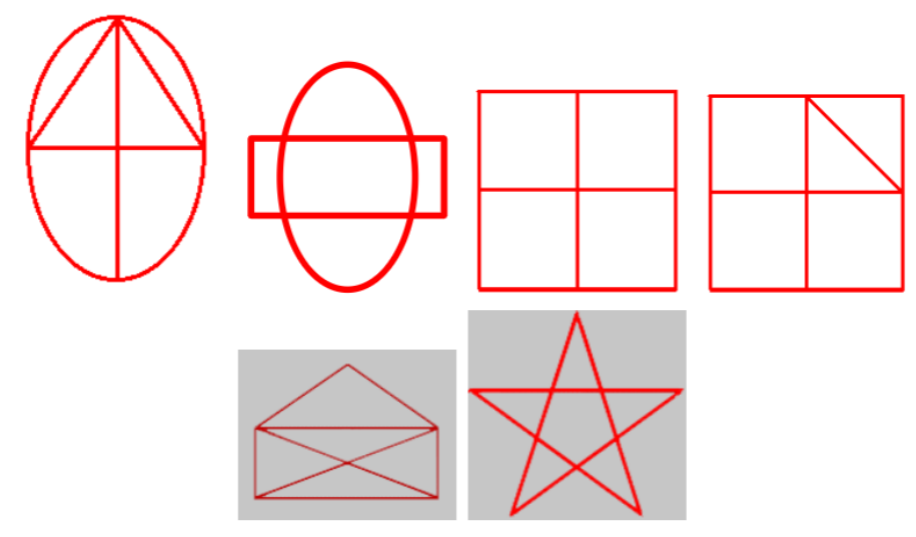

Figure 2: Graphs for Proposition 2 
Were there any graphs where you expected to find a trail with every edge but didn't? What does this suggest?

Conjecture 3: If within a graph $G$ there exists a trail containing every edge in $G$, then $G$ has precisely zero or two vertices of odd degree.

Combining Proposition 2 and Conjecture 3, can we make an even stronger conjecture?

Conjecture 4: A graph $G$ has precisely zero or two vertices of odd degree if and only if there exists a trail containing every edge of $G$.

We'll revisit this topic later in the semester...

Homework (due Monday): Writing Assignment

\section{Notes}

\footnotetext{
${ }^{1}$ Mathematicians use "Claim-Proof" form to state and logically justify an assertion of fact.

${ }^{2}$ The authors' tongue-and-cheek approach was inspired by LaRose (LaRose, 1999).

${ }^{3}$ This idea is courtesy of Crannell (Crannell et al., 2004).

${ }^{4}$ See Tiny Epic Western or Pandánte.
}

\section{References}

Bahls, P. (2012). Student writing in the quantitative disciplines: A guide for college faculty. San Francisco, CA: John Wiley \& Sons.

Bean, J. C. (2011). Engaging ideas: The professor's guide to integrating writing, critical thinking, and active learning in the classroom. San Francisco, CA: John Wiley \& Sons.

Crannell, A., LaRose, G., Ratliff, T., \& Rykken, E. (2004). Writing projects for mathematics courses: Crushed clowns, cars, and coffee to go. The Mathematical Association of America.

Georgia Southern University. (2015). Georgia southern eagles, write! Write! Write! georgia southern university quality enhancement plan.

LaRose, G. (1999). Gavin's calculus projects. Gavin's Calculus Projects. http://www.math.lsa.umich.edu/ glarose/courseinfo/calc/calcprojects.html.

Latulippe, J., \& Latulippe, C. (2014). Reduce, reuse, recycle: Resources and strategies for the use of writing projects in mathematics. PRIMUS, 24 (7), 608-625. http://doi.org/ $10.1080 / 10511970.2013 .876794$ 
Magnant, C., Nasseh, S., \& Flateby, T. (2016). Mathematical writing assignment for deeper understanding and process writing. DQP Assignment Library.

Paoletti, T. (2011). Leonard Euler's solution to the Konigsberg Bridge Problem. https://www.maa.org/book/export/html/116597.

Pinter, M. (2014). Writing to enhance understanding in general education mathematics courses. PRIMUS, 24 (7), 626-636. http://doi.org/10.1080/10511970.2014.895458

The Mathematical Association of America. (2018). MAA instructional practices guide. The Mathematical Association of America.

Walvoord, B. E. (2014). Assessing and improving student writing in college: A guide for institutions, general education, departments, and classrooms. Jossey-Bass. 